\title{
Solvent Extraction of Thorium(IV) by Didodecylphoric Acid
}

\author{
Fawwaz I. Khalili, Khaled M. Mousa and Ehsan I. Soudani
}

Department of Chemistry, University of Jordan,Amman- Jordan, Email: f_khalili99@yahoo.com.
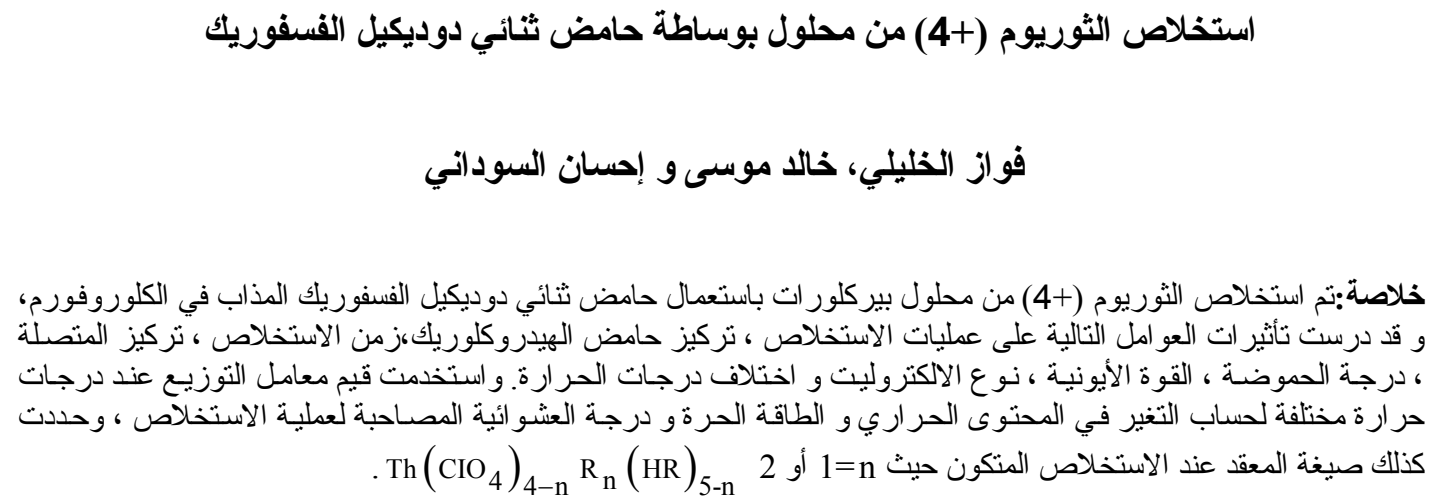

ABSTRACT: Solvent extraction of Thorium (VI) ion from perchlorate solution using didodecylphosphoric acid, DDPA, in chloroform diluent was studied. The effects of stripping hydrochloric acid concentration, stripping time, extraction time, DDPA concentration, $\mathrm{pH}$, ionic strength, supporting electrolyte and temperature on the extraction processes have been studied. From the distribution coefficient values at different temperatures, the enthalpy, the free energy and the entropy changes associated with the extraction processes were determined. The composition of the complex formed was established to be $\mathrm{Th}\left(\mathrm{ClO}_{4}\right)_{4-\mathrm{n}} \mathrm{R}_{\mathrm{n}}(\mathrm{HR})_{5-\mathrm{n}}$ where, $\mathrm{n}=1$ or 2 and $(\mathrm{HR})_{2}$ represents the dimer of DDPA.

KEYWORDS: Thorium(IV); Solvent extraction; DDPA; Thermodynamics.

\section{Introduction}

Solvent extraction enjoys a favored position among separation techniques, due to its simplicity, speed and wide scope (Dean, 1969). The distribution coefficient $\left(\mathrm{K}_{\mathrm{d}}\right)$ of a solute (A) between an organic phase and an aqueous phase is given by

$$
\mathbf{K}_{\mathbf{d}}=[\mathbf{A}]_{\mathrm{org}} /[\mathbf{A}]_{\mathrm{aq}}
$$

Generally, dialkylphosphoric acids extract uranium (VI) ion in non polar diluents by a cation exchange mechanism (Baes et al. 1958; Bunus et al. 1978; Marcus and Kolarik, 1976; Mason et al. 1970; Sato, 1965) according to the following reaction

$$
\mathrm{UO}_{2}^{2+}+2(\mathrm{HR})_{2} \square \quad \mathrm{UO}_{2}\left(\mathrm{HR}_{2}\right)_{2_{\mathrm{org}}}+2 \mathrm{H}_{\mathrm{aq}}^{+}
$$

The extraction equilibrium constant is expressed as follows

$$
\mathbf{K}_{\mathrm{ex}}=\frac{\left[\mathrm{UO}_{2}\left(\mathrm{HR}_{2}\right)_{2}\right]_{\mathrm{org}}\left[\mathbf{H}^{+}\right]_{\mathrm{aq}}{ }^{2}}{\left[\mathrm{UO}_{2}^{2+}\right]_{\mathrm{aq}}\left[(\mathbf{H R})_{2}\right]_{\mathrm{org}}^{2}}
$$


or

where

$$
\begin{gathered}
\mathbf{K}_{\mathrm{ex}}=\mathbf{K}_{\mathrm{d}}\left[\mathbf{H}^{+}\right]_{\mathrm{aq}}^{2} /\left[(\mathrm{HR})_{2}\right]_{\mathrm{org}}^{2} \\
\left.\mathbf{K}_{\mathrm{d}}=\left[\mathbf{U O}_{2}\left(\mathrm{HR}_{2}\right)_{2}\right]_{\mathrm{org}} /[\mathbf{U O}]_{2}\right]_{\mathrm{aq}}^{2+}
\end{gathered}
$$

It is well known that di(2-ethylhexyl)phosphoric acid, $\mathrm{D}_{2}$ EHPA, in many diluents is an effective extractant for actinides from mineral acid solutions (Sato ,1967; Baes,1962; Kiwan and Amin, 1973). Peppard et al. (1957a, b; 1959) have described the application of $\mathrm{D}_{2} \mathrm{EHPA}$ to the fractionation of the trivalent lanthanides plus yttrium, to the isolation of certain carrier-free radioactive $\mathrm{M}$ (III) nuclides, to the mutual separation of certain $\mathrm{M}$ (III) actinides and to the separation of Ce(IV) from M(III) actinides and lanthanides. Mason et al. (1981) studied the extraction of U(VI) and Th(IV) from an aqueous nitrate phase by bis(2,6-dimethyl-4heptyl)phosphoric acid, $\mathrm{HD}(\mathrm{DIBM}) \mathrm{P}$, in n-heptane and benzene diluents. The extraction stiochiometries and the corresponding expression for the extraction equilibrium constants were determined. The equilibrium study of extraction of lanthanide ions with didodecylphosphoric acid, DDPA, was carried out by Kondo et al. (1989). The extracted species into toluene diluent was found to be $\mathrm{LnR}_{3} .3 \mathrm{HR}$ and the extraction equilibrium constants for the three lanthanide ions, that is, samarium(III), europium (III) and gadolinium (III) were obtained.

Khaled et al. (1999) studied the extraction of U(VI) from an aqueous perchlorate phase by didodecyl phosphoric acid, (DDPA) in toluene the extracted species was found to be $\mathrm{UO}_{2}\left(\mathrm{ClO}_{4}\right)\left(\mathrm{HR}_{2}\right)(\mathrm{HR})_{2}$ where, $(\mathrm{HR})_{2}$ represents the dimer of DDPA. The optimum conditions for the extraction were studied and the thermodynamic parameters were calculated.

This work describes an investigation of the extraction of Thorium(IV) by DDPA from perchlorate solution.

\section{Experimental}

Reagents: The extractant, didodecylphosphoric acid, DDPA, was prepared and purified as described in the literature (Kondo et al. 1989).

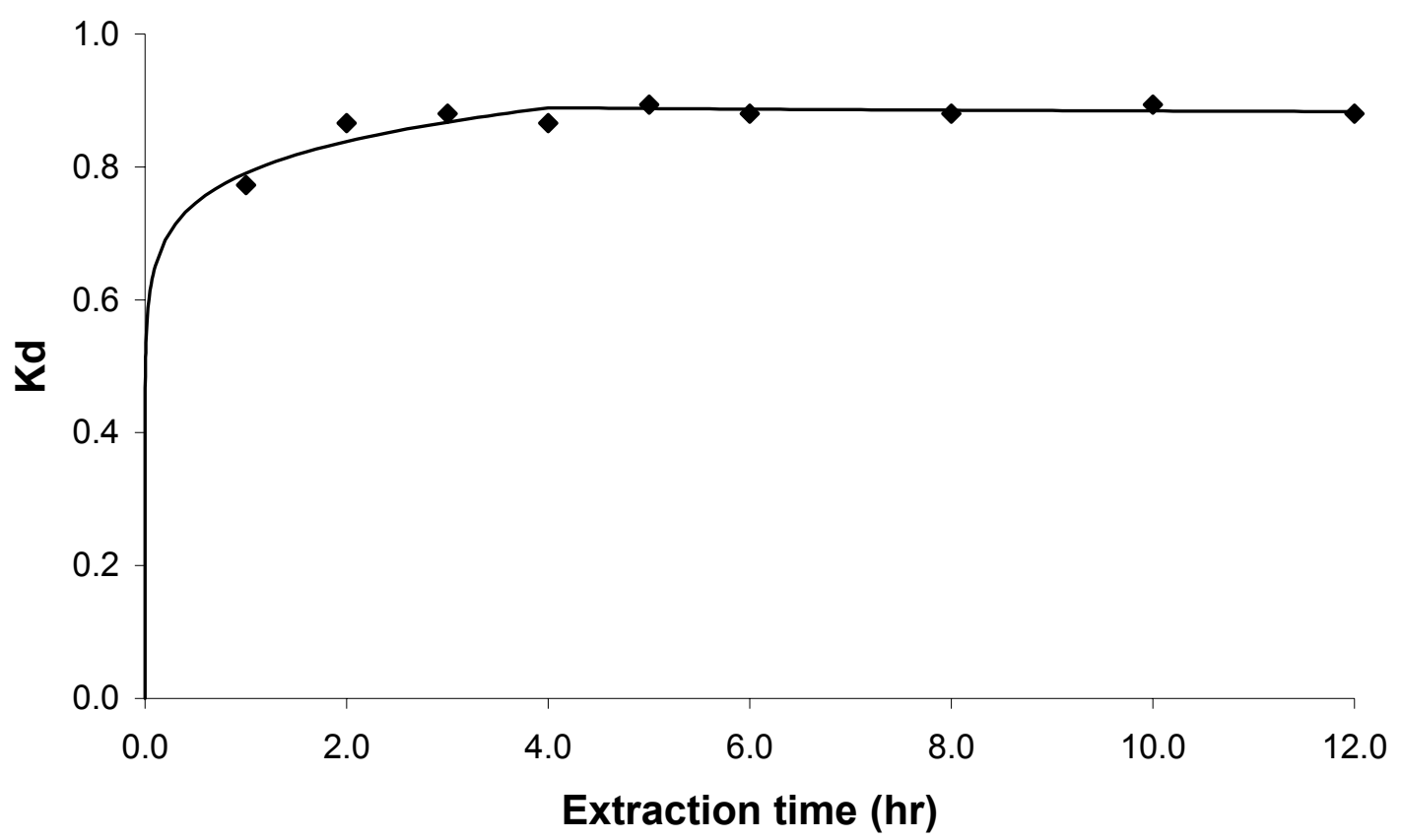

Figure 1. Variation of $\mathrm{K}_{\mathrm{d}}$ with extraction time at $25{ }^{\circ} \mathrm{C}$. 


\section{SOLVENT EXTRACTION OF THORIUM(IV)}

The organic solution was prepared by dissolving DDPA into chloroform. The aqueous solution was prepared by dissolving thorium perchlorate into perchloric acid - sodium perchlorate solution. The $\mathrm{pH}$ of the aqueous solution was adjusted using a 1.0-M perchloric acid and the ionic strength was adjusted using a 1.0-M sodium perchlorate solution. All other chemicals were of AR grade. Doubly distilled water was employed to make up aqueous solutions, and distilled water was employed for washing all glassware.

Measurement of extraction eqilibrium: Equal volumes $(10.0 \mathrm{ml})$ of the organic and aqueous solutions of known concentrations were shaken in a $30 \mathrm{ml}$ vial at a required temperature, and allowed to attain equilibrium. The thorium(IV) ion concentration in the aqueous solution was 8.0 $\mathrm{ppm}$. After about 4 hours, the two solutions were separated and aliquotes $(1.0 \mathrm{ml})$ were taken for analysis. Concentration of thorium(IV) was determined spectrophotometrically with a DU-7 spectrophotometer using 1,8- dihydroxynaphthelene-3,6-disulphonic acid-2,7-bis[(azo-2)-phenyl arsonic acid], arsenazo(III), as spectrophotometric reagent(Savvin, 1961). Scanning was performed for a standard solution of thorium-arsenazo(III) complex against a reagent blank in the range $\lambda=$ $400-800 \mathrm{~nm}$. A wavelength of $\lambda=660 \mathrm{~nm}$ was chosen to be the optimum wavelength of measurement.

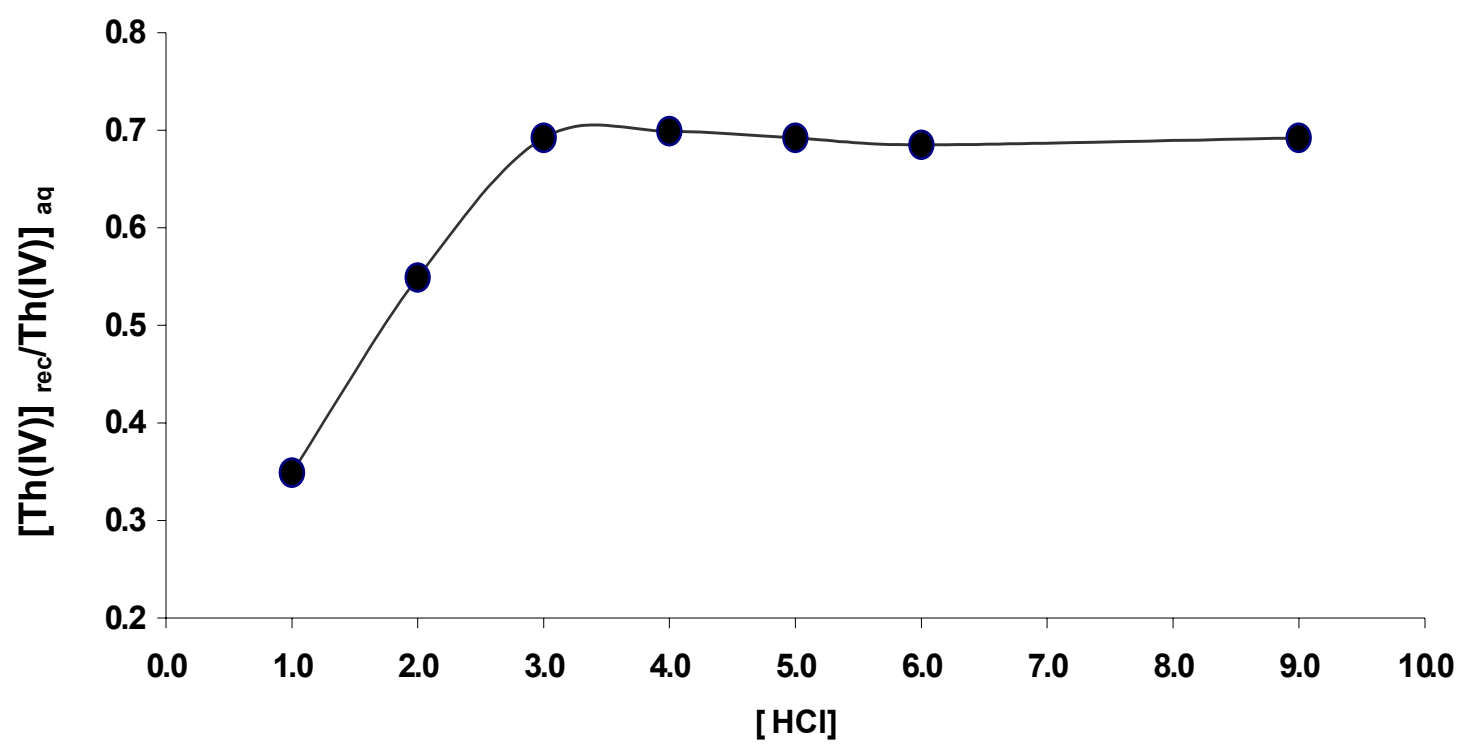

Figure 2. Variation of $\left.[\mathrm{Th}(\mathrm{IV})]_{\mathrm{rec}} / \mathrm{Th}(\mathrm{IV})\right]_{\mathrm{aq}}$ with $\mathrm{HCl}$ concentration, $[\mathrm{Th}(\mathrm{IV})]_{\mathrm{rec}}$ is the amount recovered from the organic phase.

Best extraction time was chosen by extraction of several samples of the same concentration for different periods (Figure 1). Best stripping hydrochloric acid concentration of $3.0 \mathrm{M}$ was determined by shaking $2.0 \mathrm{ml}$ of the equilibrated organic solution $\left(5.0 \times 10^{-4} \mathrm{M}\right.$ DDPA $)$ and 10.0 $\mathrm{ml}$ hydrochloric acid at different concentrations for 24 hours (Figure 2). Best stripping time was chosen by shaking $10.0 \mathrm{ml}$ of $3.0 \mathrm{M}$ hydrochloric acid solution and $2.0 \mathrm{ml}$ of the equilibrated organic solution of the same concentration $\left(5.0 \times 10^{-4} \mathrm{M}\right.$ DDPA) for different periods (Figure 3).

The best DDPA concentration was chosen by extraction of several solutions of thorium(IV) ion by extractant solutions at different concentrations (Figure 4). The optimum $\mathrm{pH}$ was chosen by extraction samples at $\mathrm{pH}$ values of $0.0,0.20,0.31,0.40,0.60,0.80$ and 1.00 (Figure 5). The effect of the ionic strength was studied by extraction of several samples at ionic strength of $0.10,0.50$, $1.00,1.50$ and $2.00 \mathrm{M}$ (Figure 6). The effect of the supporting electrolyte was studied by extraction of several samples of different supporting electrolytes of $\mathrm{NaClO}_{4}, \mathrm{NaCl}$ and $\mathrm{NaNO}_{3}$ (Figure 7). The thermodynamic parameters were obtained by studying the extraction of several samples of thorium(IV) ion at the temperatures of 20.0, 25.0, 27.7, 32.0 and $39.0 \pm 0.2{ }^{\circ} \mathrm{C}$ (Figure 8). All 
experimental data were obtained with only one variable in each experiment; the other variables were kept constant.

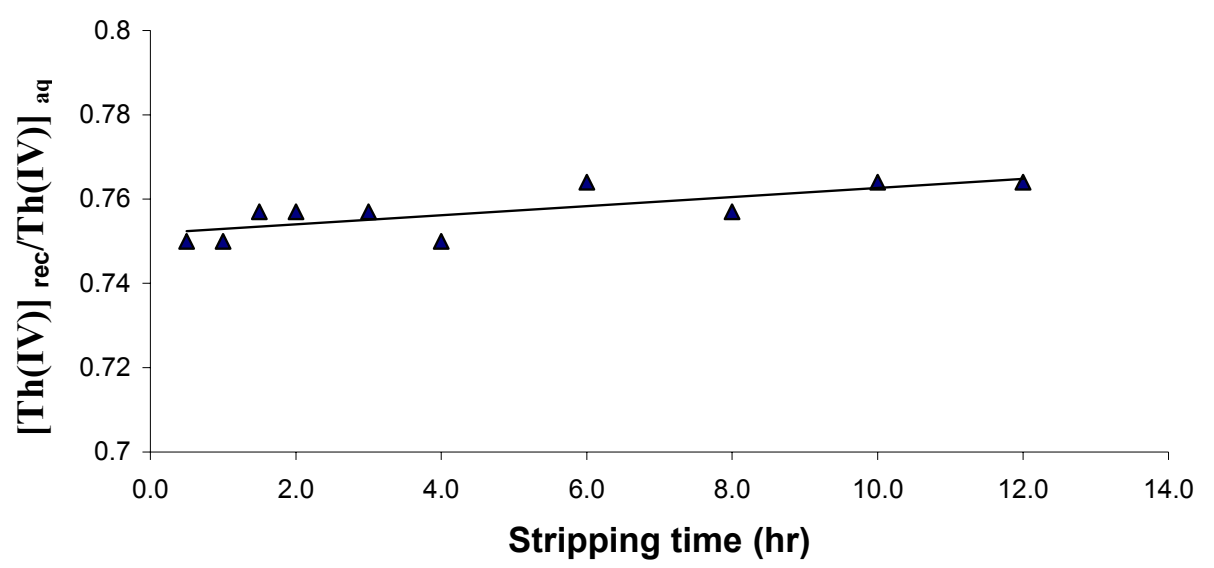

Figure 3. Variation of $\left.[\mathrm{Th}(\mathrm{IV})]_{\mathrm{rec}} / \mathrm{Th}(\mathrm{IV})\right]_{\mathrm{aq}}$ with stripping time.

\section{Results and Discussion}

Effect of extraction time: From Figure 1 establishes that equilibrium was attained in three hours, a time of four hours was selected.

Stripping of thorium(IV) from the organic phase: Hydrochloric acid solution was used for stripping of Th(IV) from the organic phase. Figures 2 and 3 demonstrate that a $3.0 \mathrm{M}$ hydrochloric acid is sufficient for stripping of Th(IV) with stripping time of at least $1 / 2$ hour, and can be confirmed by the material balance with a percentage error of about $2 \%$ or less.

Effect of extractant concentration: From Figure 4 it is seen that the $\mathrm{K}_{\mathrm{d}}$ value for Th(IV) increases with the increase of the DDPA concentration. A straight line of a slope $\approx 2.5$ was obtained. This means that 2.5 dimer molecules of DDPA are involved in the formation of the thorium-DDPA complex since DDPA has been shown to be dimeric in chloroform (Kondo et al. 1989).

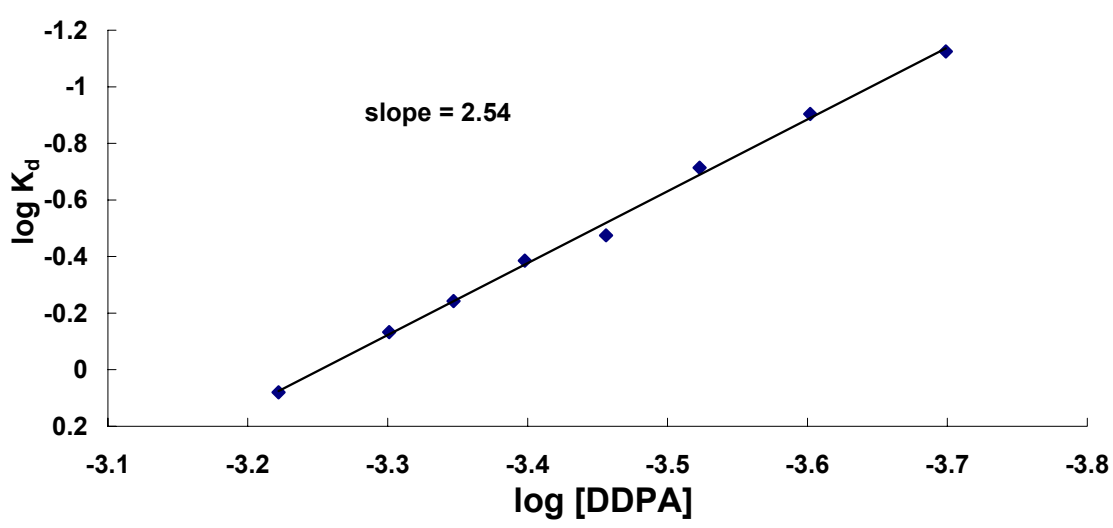

Figure 4. Variations of $\mathrm{Kd}$ with $\log [\mathrm{DDPA}]$ at $25^{\circ} \mathrm{C}$.

Effect of $p H$ : From Figure 5 it is clear that the $\mathrm{K}_{\mathrm{d}}$ value for $\mathrm{Th}(\mathrm{IV})$ is directly proportional to the $\mathrm{pH}$. This proportionality is shown for two different concentrations of DDPA $\left(3.0 \times 10^{-4}\right.$ and $4.0 \mathrm{x}$ $\left.10^{-4} \mathrm{M}\right)$ against an aqueous perchloric acid - sodium perchlorate solution of constant ionic strength of $1.0 \mathrm{M}$. 


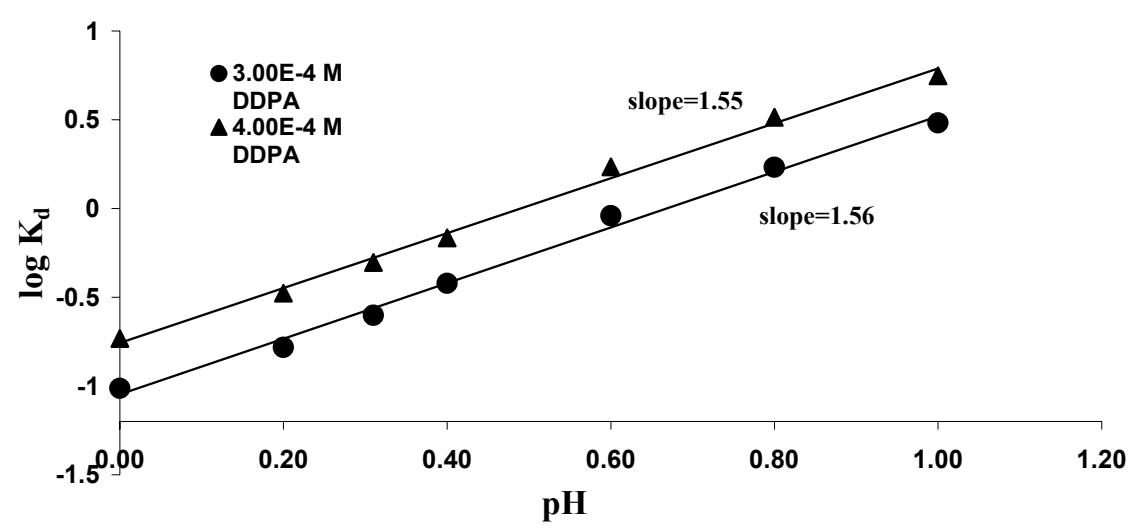

Figure 5. Variation of $\log \mathrm{K}_{\mathrm{d}}$ with $\mathrm{pH}$ at $25{ }^{\circ} \mathrm{C}$.

From the extractant dependency and the $\mathrm{pH}$ dependency, the extracted species can be written in the form $\mathrm{Th}\left(\mathrm{ClO}_{4}\right)_{4-\mathrm{n}} \mathrm{R}_{\mathrm{n}}(\mathrm{HR})_{5-\mathrm{n}}$ which means that a mixed ion exchange - solvation mechanism was involved in the extraction of Th(IV)from perchlorate solution into DDPA solution according to the following equilibrium reactions. Where $\mathrm{n}$ is equal to 1 or 2 .

$$
\operatorname{Th}\left(\mathrm{C1O}_{4}\right)_{4-\mathrm{n}_{\mathrm{aq}}}^{\mathrm{n}+}+2.5(\mathrm{HR})_{2_{\text {org }}} \square \operatorname{Th}\left(\mathrm{ClO}_{4}\right)_{4-\mathrm{n}} \mathrm{R}_{\mathrm{n}}(\mathrm{HR})_{5_{\text {org }}}+1.55 \mathrm{H}^{+}
$$

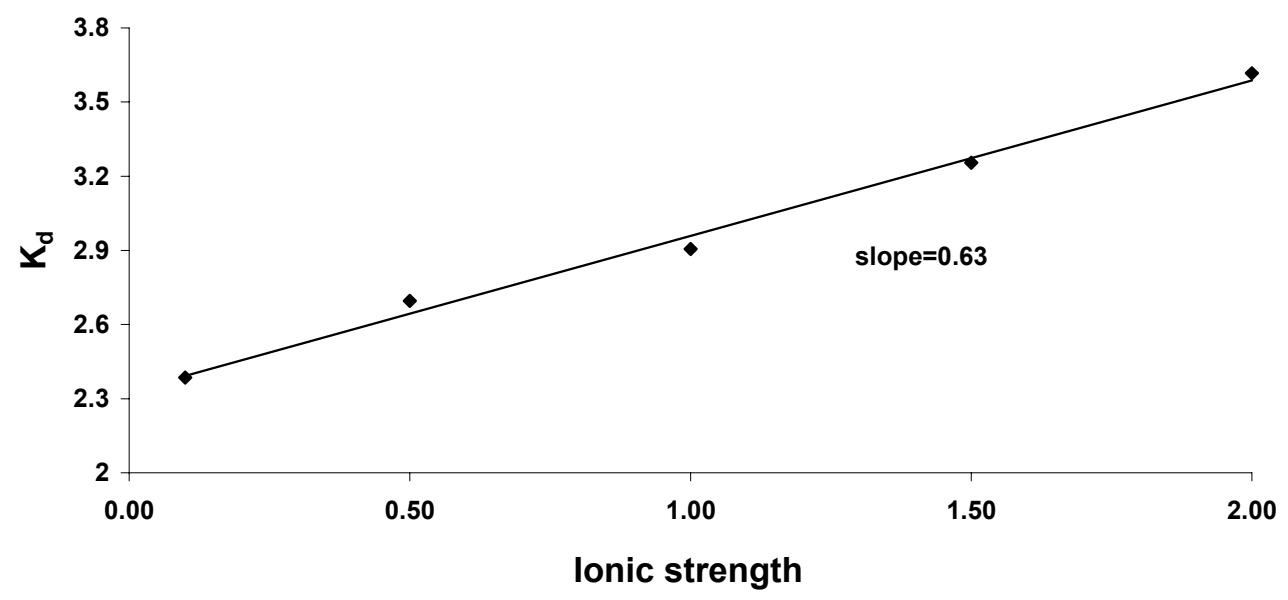

Figure 6. Variation of $K_{d}$ with ionic strength, [DDPA] $5 \times 10^{-4} \mathrm{M}$ at $25^{\circ} \mathrm{C}$.

Correspondingly, the extraction equilibrium constant is

$$
\mathrm{K}_{\mathrm{ex}}=\mathrm{K}_{\mathrm{d}}\left[\mathrm{H}^{+}\right]_{\mathrm{aq}}^{1.55} /\left[(\mathrm{HR})_{2}\right]_{\mathrm{org}}{ }^{2.5}
$$

Where, $\left[\mathrm{H}^{+}\right]$is the concentration of the hydrogen ion in the aqueous phase, $\mathrm{K}_{\mathrm{d}}$ is the distribution coefficient and $\left[(\mathrm{HR})_{2}\right]$ org is the concentration of DDPA dimer in the organic phase at equilibrium. Substitution of the previous values in equation (3) gives Kex $=1.27 \times 10^{7}$. A similar mechanism was found by many authors (Kiwan et al, 1971; Marcus et al. 1973) for the extraction of Th(IV) by dialkylphosphoric acid extractant.

Effect of ionic strength: Figure 6 shows that the $\mathrm{K}_{\mathrm{d}}$ increases as the ionic strength (I) increases. This is explained by the increase of the thermodynamic activity of the metal salt extracted and the decrease of the activity of water as the ionic strength increases (Kolarik, 1982). 
Effect of supporting electrolyte: From the data shown in Figure 7 it is clear that the extraction of thorium(IV) ion from both perchlorate and nitrate solution is approximately the same and easier than the extraction of thorium(IV) ion from chloride solution. Moreover, the same slope of about 2.5 in three cases, means that the mechanism of the extraction is independent of the supporting electrolyte present in the aqueous phase.

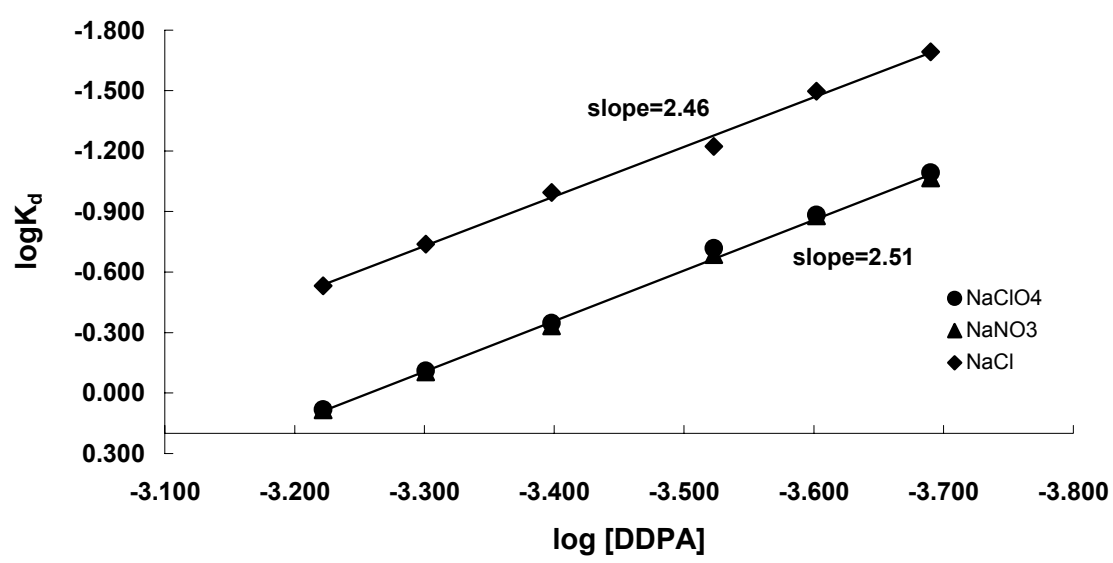

Figure 7. Variation of $\log \mathrm{K}_{\mathrm{d}}$ with $\log$ [DDPA] for different supporting electrolyte, [DDPA] $5 \times 10^{-}$ ${ }^{4} \mathrm{M}$ at $25^{\circ} \mathrm{C}$.

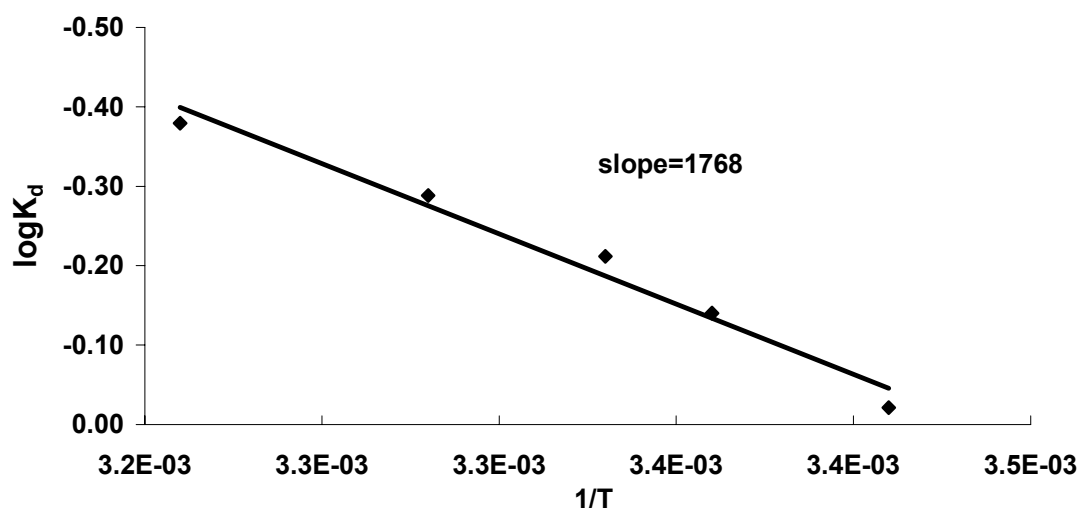

Figure 8. Variation of $\log \mathrm{K}_{\mathrm{d}}$ with $1 / \mathrm{T}$, $[\mathrm{DDPA}]=5 \times 10^{-4} \mathrm{M}$.

Effect of temperature: It is seen from the data in Figure 8 that the $\mathrm{Kd}$ values decrease with increasing temperature, which is in agreement with the behavior reported for the extraction of Th(IV) ion (Mason et al,1981).

The Van't Hoff's equation in the form given by equation (8) can be used to calculate the enthalpy change $(\Delta \mathrm{H})$ associated with extraction of Th(IV).

$$
\frac{\Delta \log K}{\Delta(1 / T)}=\frac{\Delta H^{\circ}}{2.303 R}
$$

The plot of $\log \mathrm{K}_{\mathrm{d}}$ vs. $1 / T$ is shown in Figure 8. The plot is linear in agreement with equation (8). The value of $\Delta \mathrm{H}$ obtained from this plot using least squares method is $-33.9 \pm 0.8 \mathrm{~kJ} \mathrm{~mol}^{-1}$. It is seen that extraction of Th(IV) is exothermic. The values of free energy and entropy changes were 
calculated using equations (9) and (10)

$$
\begin{aligned}
& \Delta G^{\circ}=-R T \text { In } K \\
& \Delta G^{\circ}=\Delta H^{\circ}-T \Delta \mathrm{S}^{\circ}
\end{aligned}
$$

and these values were found to be $\mathrm{AG}^{\mathrm{o}}=-40.5 \pm 2.1 \mathrm{~kJ} \mathrm{~mol}^{-1}$ and $\Delta \mathrm{S}^{\mathrm{o}}=22.1 \pm 5.3 \mathrm{JK}^{-1} \mathrm{~mol}^{-1}$. A positive entropy change accompanies the dehydration of Th(IV) ion which is known to be highly hydrated. The extraction system was found to be spontaneous. This is in agreement with our previous work for U(VI) (Khaled et al 1999).

\section{Conclusion}

The equilibrium study of the extraction of thorium(IV) ion with didodecylphosphoric acid was carried out. The extracted species into chloroform diluent was found to be $\mathrm{Th}\left(\mathrm{ClO}_{4}\right)_{4-\mathrm{n}} \mathrm{R}_{\mathrm{n}}(\mathrm{HR})_{5 \text {-n }}$ where, $\mathrm{n}=1$ or 2 and $(\mathrm{HR})_{2}$ represents the dimer of DDPA. The extraction equilibrium constant was obtained and the extraction system was found to be spontaneous due to the positive entropy change as well as the negative enthalpy change which favors the extraction of Th(IV) ion.

\section{References}

BAES, C.F. Jr. 1962. The Extraction of Metallic Species by Dialkylphosphoric Acids. $J$. Inorg. Nucl. Chem. 24: 707-720.

BAES, C.F. Jr., ZINGARO, R.A and COLEMAN, C.F. 1958. . The Extraction of Uranium(VI) from Acid Perchlorate Solutions by Bis(2-ethylhexyl)phosphoric Acid in Hexane. J. Phys. Chem. 62: 129-136.

BUNUS, F.T., DOMOCOS, V.C and DUMITRESCU, P. 1978. Synergic Extraction of Uranium from Phosphate Solutions with Di-(2-ethylhexyl)phosphoric Acid and Tri-noctylphosphine Oxide. J. Inorg. Nucl. Chem. 40: 117-121.

DEAN, J.A. 1969.Chemical Separation Methods, pp. 18-44. Van Nostrand Reinhold, New York.

KHALED, M.M and KHALILI, F.I. 1999. Solvent Extraction of Uranium(VI) by Didodecylphosphoric Acid. Science and Technology. 4:15-21.

KIWAN, A.M and AMIN, R.S. 1973. Extraction of Uranium(VI) by Di-(2ethylhexyl)phosphoric Acid from Perchloric Acid Solutions. J. Inorg Nucl. Chem. 35: 3315-3321.

KOLARIK, Z. 1982. Gmelin Handbook of Inorganic Chemistry. Vol. D2, 8th. Edition, p. 34. Springer-Verlag, Berlin.

KONDO K, MOMOTA, K. and NAKASHIO, T. 1989. Equilibrium of Solvent Extraction of Lanthanides with Didodecylphosphoric Acid. Solvent Ext. Ion Exch. 7: 1027-1041.

LUGININ, V.A and TSERKOVIINTSKAYA, I.A. 1976. Mechanism of the Extraction of Uranium(VI) by Di-(2-ethylhexyl)phosphoric Acid from Mineral Acid Solutions. Porb. Soverm. Anal. Khim. 1: 148-155.

MARCUS, Y., and KOLARIK, Z. 1976. Thermodynamics of Liquid-Liquid Distribution Reactions-III. J Inorg Nucl Chem. 38: 1069-1073.

MASON, G.W., GRIFFIN, H.E and LEWEY, S.M. 1981. J. Inorg. Nucl. Chem. 43: 391-395.

MASON, G.W., SCHOFER, N.L and PEPPARD, D.F. 1970. The Extraction of U(VI) and Selected M(III) Cations by Bis Neo-octylphosphoric Acid in Two Different Hydrocarbon Diluents. J. Inorg Nucl Chem. 32: 3911-3922.

PEPPARD, D.F., MASON, G.W. DRISCOLL, W.J and MCCARTY, S. 1959. Extraction of Thorium(IV) by Di Esters of Orthophosphoric Acid. J. Inorg. Nucl. Chem. 13: 138-150.

PEPPARD, D.F., MASON, G.W. MAIEER, J.L and DRISCOLL, W.J. 1957. Fractional Extraction of the Lanthanides as their Di-alkylorthophosphates. J. Inorg. Nucl. Chem. 4: 334-343.

ROZEN, A.M., MARTYNOV, B.V. ANIKIN, V.I and MAMAEV, L.A. 1973. Extraction 
Capability of Sulfoxides. Soviet Radiochem. 15: 121-123.

SATO, T. 1965. The Extraction of Uranium(VI) from Hydrochloric Acid Solutions by Di-(2ethylhexyl)phosphoric Acid. J. Inorg. Nucl. Chem. 27: 1853-1860.

SATO, T. 1967. The Extraction of Thorium from Nitric Acid Solutions by Di-(2ethylhexyl)phosphoric Acid. J. Inorg Nucl. Chem. 29: 555-563.

SAVVIN, S.B. 1961. Analytical Use of Arsenazo(III). Talanta. 8: 673-685.

Received 15 December 2002

Accepted 24 October 2003 